\title{
Cluster of Differentiation 274 Antigen Immunohistochemical Expression in Tumor and Peri-tumor Cells of Hodgkin and Non-Hodgkin Lymphoma and Clinicopathological Relation (Single-center Study)
}

\author{
Walaa Ghanam ${ }^{1}{ }^{1}$, Shaimaa M. M. Bebars $\mathbb{D}^{2 *}$ \\ ${ }^{1}$ Department of Pathology, Faculty of Medicine, Suez University, Suez, Egypt; ${ }^{2}$ Department of Pathology, Faculty of Medicine, \\ Aswan University, Aswan, Egypt
}

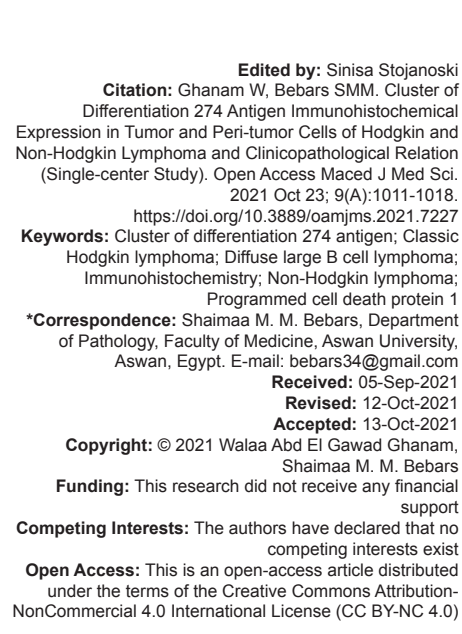

Introduction

Cluster of differentiation 274 (CD274) antigen is one of two ligands for programmed cell death protein 1 (PD-1), a receptor representing the second checkpoint of immune response that decreases the function of effector T-cell in tissues [1]. CD274 antigen was recognized in variable tumors, and researchers have been investigating its regulation. An example of such a regulation mechanism is interferon-gamma (IFN $\gamma$ ) that induces CD274 antigen surface expression on tumor cells [2].

Although CD274 antigen is not normally expressed on epithelial cells, it can be detected on the surface of many neoplastic cells, such as its expression in $20 \%$ of triple-negative breast cancer cases [2] and $20 \%$ of urothelial carcinoma [3]. Researchers pointed out that utilizing monoclonal antibodies such as CD274 antigen-targeted treatment could obstruct the pathway of CD274 antigen inhibitory effects and induce T cell activating functions, thus improving prognosis in cancer patients [4]. Furthermore, tumor expression of CD274 antigen is considered predictive of therapy response [5]. Anti-PD-1 targeted therapy succeeded in improving the prognosis and outcomes in tumors with CD274 antigen high expression by immunohistochemistry (IHC) [6].

Lymphoma is a common concern worldwide. Non-Hodgkin lymphoma (NHL) represents the fifth to ninth most frequent malignancy globally. However, the frequency of the subtypes differs according to the country [7]. In adults, diffuse large B-cell lymphoma (DLBCL) is the most frequently encountered type of NHL. Treatment with chemotherapy gives the opportunity of $60-70 \%$ overall survival for 5 years in such cases [8]. NHL has a heterogeneous nature 
regarding genetics and prognosis. Sub-classification into the germinal center and non-germinal center could be helpful regarding prognostic prediction by IHC tissue microarray (TMA) application [9]. However, new markers are still needed, particularly for estimating prognosis and targeted therapy [10]. Conversely, Hodgkin lymphoma (HL) is not considered a common lymphoma according to the worldwide report of 79,990 newly registered cases $(0.4 \%$ of all tumors), and $0.3 \%$ of all deaths of cancer recognized in 2018 [11].

In Egypt, lymphoma represents one of the world's highest incidence rates, with a NHL incidence rate of $5 \%$. It ranks the fourth most frequent adults tumor, as $\mathrm{NHL}$ represents $76.6 \%$, while $\mathrm{HL}$ is found in the rest of lymphoma cases [12]. While less incidence of $\mathrm{HL}$ was reported in underdeveloped regions, mortality rates are elevated in contrary to developed regions of the world [11]. Moreover, the relapse and refractory stage of the disease was experienced in 10-30\% of HL treated cases [13]. Hence, there is a significant need for research to help decrease the incidence of $\mathrm{HL}$ and develop lines of treatment with the incorporation of more targeted therapy.

In variable lymphoma cell lines, CD274 antigen blockade showed a decline of proliferation effect. Such effect proposes a significant role for CD274 antigen expression in tumorigenesis of lymphoma [14]. There is variability in reports of CD274 antigen expression in NHL tumors with a wide range of expression from as low as $10.5 \%$ to near two-third of NHL tumor cells (61.1\%) [15], [16], [17]. According to Menter et al., CD274 antigen was reported in $31 \%$ of primary DLBCL and $35 \%$ of 1 ry B-cell lymphomas of mediastinal type. In HL; it was reported as $70 \%$ of classic HL, $54 \%$ of nodular lymphocytepredominant HL [17]. Thus, the variability of results of CD274 antigen expression in lymphoma requires investigation. The purpose of this study is to explore and compare the immunohistochemical expression of CD274 antigen in tumor and peri-tumor cells of classic HL and NHL (DLBCL) cases and its relation with available clinicopathological data.

\section{Materials and Methods}

\section{Material of this study}

For this study, all excision biopsy cases of lymphoma submitted in the hospital were collected as paraffin-embedded blocks in a retrospective manner from January 2016 to December 2019. All cases were examined, and available data regarding age, sex, history, clinical, serological, and radiological findings were obtained from patient's data records. All cases were anonymous and handled according to legal and ethical standards.

\section{Exclusion criteria}

Core or incision biopsy and cases with insufficient clinical data or paraffin blocks with deficient material suitable for immunohistochemical staining were not included in the study. Furthermore, cases of patients who received therapy and gray zone lymphoma cases were excluded from the study.

This retrospective work was carried out on 78 cases of performed lymph node (LN) excision biopsy of the whole node or multiple nodes after the approval of an institutional ethical committee of research was obtained.

\section{Methods}

\section{Histopathological examination}

Whole sections of LN were prepared using $\mathrm{H}$ and $\mathrm{E}$ staining and submitted for histopathological examination to confirm the diagnosis of lymphoma and selection of the most cellular areas with malignant cells to be prepared for the TMA blocks after confirmation of the lymphoma type using immunophenotyping (CD 20, CD 3, CD 15, CD 30, CD5, CD23). Furthermore, 10 complete sections (5 from each type of lymphoma) were prepared to be treated with CD274 antigen IHC to compare complete section results with that of TMA.

\section{Methodology for TMA}

TMA was performed using the known manual method of punching a core from donor paraffin block, then embedded into a "recipient block". Screening of donor blocks for adequate thickness and content of tissue was performed first [18]. TMA map was designed according to each donor block core location and orientation, and it was recorded before the construction of TMA. According to this map, cores punched from donor blocks were then embedded into the corresponding hole in the recipient block. Two TMA blocks from each type of lymphoma were constructed [18]. Sections cut from the recipient TMA block have the same predesigned map orientation.

\section{CD274 antigen IHC}

Prepared sections from constructed microarray blocks, and 10 complete sections from cases of classic $\mathrm{HL}$ and NHL (DLBCL) for comparison (5 of each) were applied through the auto-stainer for CD274 antigen IHC using monoclonal rabbit anti-human CD274 antigen (PD-L1 ZR3-ASR, diluted in Tris buffer, PH.33.7 with $1 \%$ BSA and $<0.7 \%$ sodium azide, a Sigma Aldrich company). 


\section{Interpretation of IHC}

Assessment of CD274 antigen IHC results in tumor cells was performed according to Herbst et al. and Kwon et al. [5], [19] as follow:

1. The percentage of the cells displaying membranous and/or cytoplasmic staining was evaluated as no or any staining $<10 \%$ of tumor cells were considered negative, and staining of more than or equal to $10 \%$ of tumor cells was considered positive. In addition, the intensity of membranous staining with cytoplasmic accentuation was reported as follows: 0 ; No staining, +1 ; mild, +2 ; moderate and +3 ; strong

2. Distribution through tumor-infiltrating cells (peri-tumor) was scored as follow: 0 , no positive cells/high-power field (HPF); 1: no more than 10 positive cells/HPF; 2: 10-30 positive cells/HPF; 3 : more than 30 positive cells per HPF. Then final interpretation was scored as negative or positive results.

\section{Statistical analysis of the data}

Data were fed to the computer and analyzed using IBM SPSS software package version 20.0. (Armonk, NY: IBM Corp). The Kolmogorov-Smirnov test was used to verify the normality of variables distribution; comparisons between groups for categorical variables were assessed using the Chi-square test (Fisher or Monte Carlo). Student t-test was used to compare two groups for normally distributed quantitative variables. The significance of the achieved results was judged at the $5 \%$ level.

\section{Results}

In this study, we investigated a total of 78 cases of lymphoma (48 cases of classic HL and 30 cases of $\mathrm{NHL}$ DLBCL). All patient records of the studied lymphoma groups are summarized in (Table 1). The 10 complete sections IHC results were the same as obtained by TMA. As shown in Table 1,53.8\% of all studied lymphoma cases showed positive CD274 antigen expression. There is a significant difference when comparing CD274 antigen-positive and negative cases in classic $\mathrm{HL}$ and $\mathrm{NHL}$ (DLBCL) as two-third of $\mathrm{HL}$ cases expressed CD274 antigen. At the same time, one-third of NHL showed positivity $(p=0.004)$. In addition, there was a significant difference when comparing different intensities of CD274 antigen expression in $\mathrm{HL}$ and $\mathrm{NHL}$ patients $(p<0.001)$. Strong intensity of CD274 antigen expression was detected in $30.8 \%$ of all studied cases and was more common in $\mathrm{HL}$ cases $(50 \%)$. Almost half of the peri-tumor microenvironment cells $(48.7 \%)$ showed positive CD274 antigen expression with significantly more frequent expression in $\mathrm{HL}$

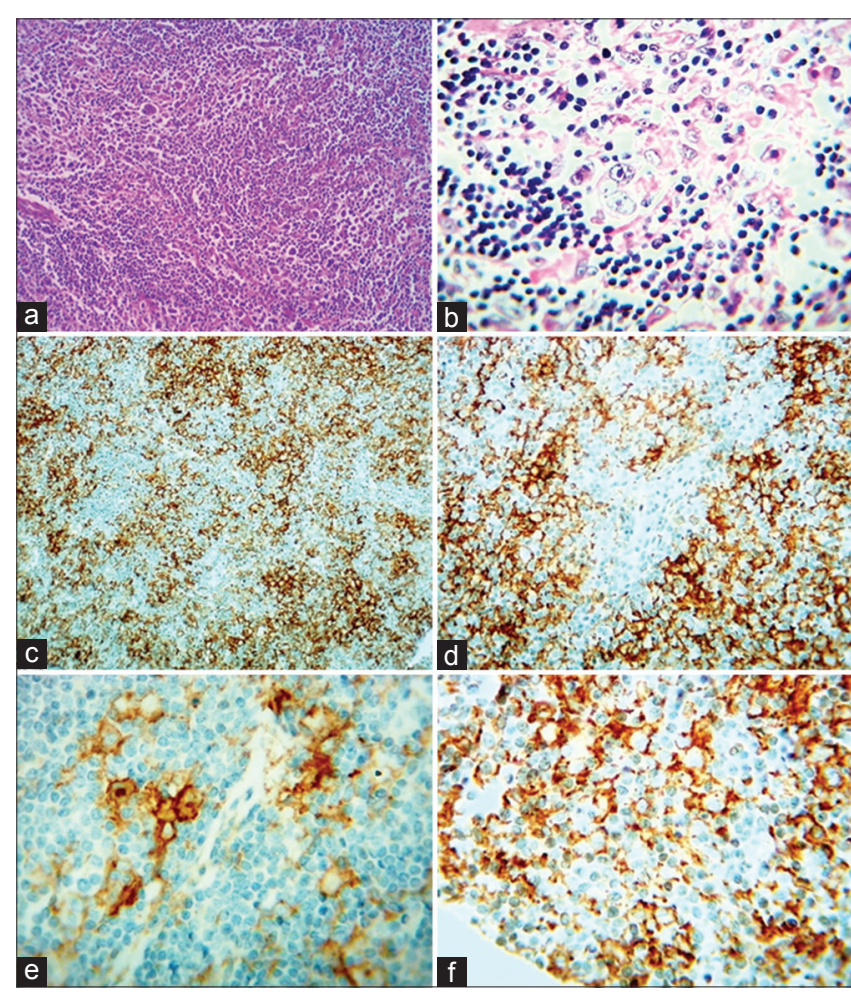

Figure 1: Hodgkin lymphoma: (a) hematoxylin and eosin ( $H$ and $E$ ) of Hodgkin lymphoma with scattered RS cells $(\times 100)$. (b) $H$ and $E$ Hodgkin lymphoma (×400). (c) Cluster of differentiation 274 (CD274) antigen-positive RS cells of moderate-intensity $(\times 100)$. (d) CD274 antigen moderate and strong intensity (×200). (e) CD274 antigen strong intensity RS cells (×400). (f) CD274 antigen strong intensity peri-tumor cells $(\times 400)$

cases $(p=0.002)$ (Figures 1 and 2). When comparing positive and negative CD274 antigen cases in relation to different clinical parameters, only serological findings showed significant difference $(p<0.001)$, with combined elevated erythrocyte sedimentation rate (ESR) and lactate dehydrogenase (LDH) being found in two-third of positive CD274 antigen cases (Table 2).

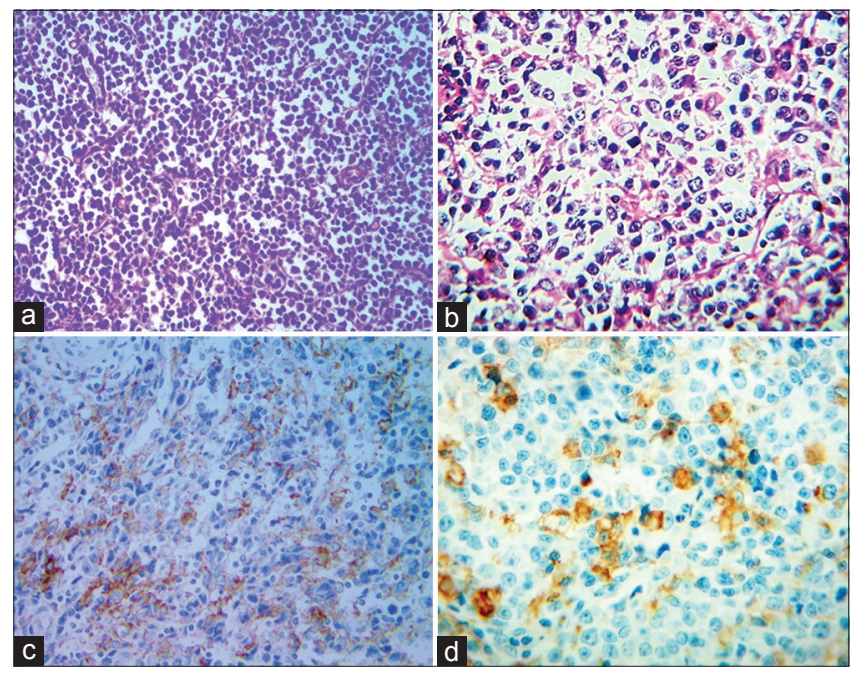

Figure 2: Non-Hodgkin lymphoma: (a) hematoxylin and eosin (Hand E) of Non-Hodgkin lymphoma (×200). (b) $H$ and $E$ of Non-Hodgkin lymphoma $(\times 400)$. (c) Cluster of differentiation 274 (CD274) antigen-positive tumor cells of mild and moderate intensity $(\times 200)$. (d) CD274 antigen-positive tumor cells of moderate-intensity $(\times 400)$ 
Table 1: Comparison between the two lymphoma groups according to different parameters

\begin{tabular}{|c|c|c|c|c|c|}
\hline Clinicopathological parameters & Total $(n=78)$ & HL classic $(n=48)$ & NHL DLBCL $(n=30)$ & Test of sig. & $\mathrm{p}$ \\
\hline \multicolumn{6}{|l|}{ Age (years) } \\
\hline Median (Min.-Max.) & $45(17-66)$ & $28.5(17-65)$ & $55(48-66)$ & \multirow[t]{2}{*}{$\mathrm{t}=9.820^{*}$} & \multirow[t]{2}{*}{$<0.001^{*}$} \\
\hline Mean \pm SD & $42.6 \pm 15.8$ & $34 \pm 13.8$ & $56.4 \pm 6$ & & \\
\hline \multicolumn{6}{|l|}{$\operatorname{Sex}(\%)$} \\
\hline Male & $46(59)$ & $40(83.3)$ & $6(20)$ & \multirow[t]{2}{*}{$\chi^{2}=30.607^{*}$} & \multirow[t]{2}{*}{$<0.001^{*}$} \\
\hline Female & $32(41)$ & $8(16.7)$ & $24(80)$ & & \\
\hline \multicolumn{6}{|l|}{ Site (\%) } \\
\hline Cervical LN & $42(53.8)$ & $34(70.8)$ & $8(26.7)$ & \multirow[t]{3}{*}{$\chi^{2}=14.498^{*}$} & \multirow[t]{3}{*}{$0.001^{*}$} \\
\hline Axillary LN & $26(33.3)$ & $10(20.8)$ & $16(53.3)$ & & \\
\hline Inguinal LN & $10(12.8)$ & $4(8.3)$ & $6(20)$ & & \\
\hline \multicolumn{6}{|l|}{ Clinical symptoms (\%) } \\
\hline Swelling & $44(56.4)$ & $20(41.7)$ & $24(80)$ & \multirow[t]{2}{*}{$\chi^{2}=11.033^{*}$} & \multirow[t]{2}{*}{$0.001^{*}$} \\
\hline Fever and swelling & $34(43.6)$ & $28(58.3)$ & $6(20)$ & & \\
\hline \multicolumn{6}{|l|}{ Serological data received (\%) } \\
\hline No serological findings & $30(38.5)$ & $6(12.5)$ & $24(80)$ & \multirow{4}{*}{$\chi^{2}=40.582^{*}$} & \multirow[t]{4}{*}{$<0.001^{*}$} \\
\hline Elevated ESR & $12(15.4)$ & $8(16.7)$ & $4(13.3)$ & & \\
\hline Elevated LDH & $2(2.6)$ & $2(4.2)$ & $0(0)$ & & \\
\hline Elevated ESR and elevated LDH & $34(43.6)$ & $32(66.7)$ & $2(6.7)$ & & \\
\hline \multicolumn{6}{|l|}{ Radiological findings received (\%) } \\
\hline Localized lymphadenopathy & $66(84.6)$ & $40(83.3)$ & $26(86.7)$ & \multirow[t]{2}{*}{$\chi^{2}=0.158$} & \multirow[t]{2}{*}{0.758} \\
\hline Generalized lymphadenopathy & $12(15.4)$ & $8(16.7)$ & $4(13.3)$ & & \\
\hline \multicolumn{6}{|l|}{ CD274 antigen IHC results } \\
\hline Negative & $36(46.2)$ & $16(33.3)$ & $20(66.7)$ & \multirow[t]{2}{*}{$\chi^{2}=8.254^{*}$} & \multirow[t]{2}{*}{$0.004^{*}$} \\
\hline Positive & $42(53.8)$ & $32(66.7)$ & $10(33.3)$ & & \\
\hline \multicolumn{6}{|l|}{ Intensity of staining (\%) } \\
\hline Negative & $36(46.2)$ & $16(33.3)$ & $20(66.7)$ & \multirow[t]{4}{*}{$\chi^{2}=26.809^{*}$} & \multirow[t]{4}{*}{$<0.001^{*}$} \\
\hline Mild & $6(7.7)$ & $2(4.2)$ & $4(13.3)$ & & \\
\hline Moderate & $12(15.4)$ & $6(12.5)$ & $6(20)$ & & \\
\hline Strong & $24(30.8)$ & $24(50)$ & $0(0)$ & & \\
\hline \multicolumn{6}{|l|}{ Peri-tumor microenvironment (\%) } \\
\hline Negative & $40(51.3)$ & $18(37.5)$ & $22(73.3)$ & \multirow[t]{2}{*}{$\chi^{2}=9.488^{*}$} & \multirow[t]{2}{*}{$0.002^{*}$} \\
\hline Positive & $38(48.7)$ & $30(62.5)$ & $8(26.7)$ & & \\
\hline
\end{tabular}

Table 2: Relation between CD274 antigen IHC and different parameters in total lymphoma cases ( $\mathrm{n}=78$ )

\begin{tabular}{|c|c|c|c|c|}
\hline \multirow[t]{2}{*}{ Clinical data } & \multicolumn{2}{|l|}{ CD274 antigen IHC } & \multirow[t]{2}{*}{ Test of Sig. } & \multirow[t]{2}{*}{$p$} \\
\hline & Negative $(n=36)$ & Positive $(n=42)$ & & \\
\hline \multicolumn{5}{|l|}{ Age (years) } \\
\hline Median (Min.-Max.) & $49(19-66)$ & $33(17-64)$ & \multirow[t]{2}{*}{$t=1.483$} & \multirow[t]{2}{*}{0.142} \\
\hline Mean \pm SD & $45.4 \pm 13.9$ & $40.2 \pm 17.1$ & & \\
\hline \multicolumn{5}{|l|}{$\operatorname{Sex}(\%)$} \\
\hline Male & $22(61.1)$ & $24(57.1)$ & \multirow[t]{2}{*}{$\chi^{2}=0.126$} & \multirow[t]{2}{*}{0.722} \\
\hline Female & $14(38.9)$ & $18(42.9)$ & & \\
\hline \multicolumn{5}{|l|}{ Clinical symptoms (\%) } \\
\hline Swelling & $22(61.1)$ & $22(52.4)$ & \multirow[t]{3}{*}{$\chi^{2}=0.601$} & \multirow[t]{2}{*}{0.438} \\
\hline Fever and swelling & $14(38.9)$ & $20(47.6)$ & & \\
\hline \multicolumn{4}{|l|}{ Serological data received (\%) } & \\
\hline No serological findings & $22(61.1)$ & $8(19)$ & \multirow[t]{4}{*}{$\chi^{2}=23.977^{*}$} & \multirow[t]{4}{*}{$<0.001^{*}$} \\
\hline Elevated ESR & $8(22.2)$ & $4(9.5)$ & & \\
\hline Elevated LDH & $0(0)$ & $2(4.8)$ & & \\
\hline Elevated ESR and elevated LDH & $6(16.7)$ & $28(66.7$ & & \\
\hline
\end{tabular}

When comparing positive and negative CD274 antigen IHC results in different parameters found in cases of classic $\mathrm{HL}$, gender and serological findings showed significant difference $(p=0.039$ and $p<0.001$, respectively), with combined elevated ESR and LDH being found in $87.5 \%$ of positive CD274 antigen HL cases (Table 3). While, when comparing positive and negative CD274 antigen staining results in different parameters of the NHL (DLBCL) group, only age showed a significant difference $(p<0.001)$ (Table 3$)$.

\section{Discussion}

Lymphoma represents a heterogeneous neoplastic group with various manifestations, predictions, and treatment responses. Possibly more than any other type of malignancy, lymphoma diagnosis and prognosis implicate incorporating clinical presentations, histologic criteria, immunophenotyping, and even molecular and cytogenetic findings. A precise lymphoma diagnosis and identification of new markers typically permit appropriate patient categorization and treatment [20]. Thus, many researchers have been working to recognize biomarkers of a checkpoint blockade immune response, to categorize patients who are most probably benefiting from such immune therapy. Recently, CD274 antigen has been studied in different tumors to predict targeted immunotherapy and prognostic criteria. However, CD274 antigen expression and effect in lymphoma showed wide variations in results [5], [6], [15], [16], [17].

This study detected a significant difference between $\mathrm{HL}$ and $\mathrm{NHL}$ cases, as $\mathrm{NHL}$ patients were two decades older than $\mathrm{HL}$ patients. Furthermore, there was a significant difference regarding gender with male predominance in $\mathrm{HL}$ patients. Cervical LN was the most affected site, especially in HL patients, while axillary LN was affected more in NHL cases $(p=0.001)$. A significant difference was detected 
Table 3: Relation between CD274 antigen IHC and different parameters in classic Hodgkin Lymphoma group $(n=48)$ and Non-Hodgkin lymphoma group $(n=30)$

\begin{tabular}{|c|c|c|c|c|}
\hline \multirow[t]{2}{*}{ Clinical data } & \multicolumn{2}{|c|}{ CD274 antigen IHC in classic Hodgkin Lymphoma $n=48$} & \multirow[t]{2}{*}{ Test of Sig. } & \multirow[t]{2}{*}{$\mathrm{p}$} \\
\hline & Negative $(n=16)$ & Positive $(n=32)$ & & \\
\hline \multicolumn{5}{|l|}{ Age (years) } \\
\hline Median (Min.-Max.) & $28.5(19-65)$ & $29(17-63)$ & \multirow{2}{*}{$t=0.336$} & \multirow{2}{*}{0.738} \\
\hline Mean \pm SD. & $35 \pm 14.2$ & $33.6 \pm 13.8$ & & \\
\hline \multicolumn{5}{|l|}{ Sex $(\%)$} \\
\hline Male & $16(100)$ & $24(75)$ & \multirow[t]{2}{*}{$\chi^{2}=4.800^{*}$} & \multirow[t]{2}{*}{$0.039^{*}$} \\
\hline Female & $0(0)$ & $8(25)$ & & \\
\hline \multicolumn{5}{|l|}{ Clinical symptoms (\%) } \\
\hline Swelling & $6(37.5)$ & $14(43.8)$ & \multirow[t]{2}{*}{$\chi^{2}=0.171$} & \multirow[t]{2}{*}{0.679} \\
\hline Fever and swelling & $10(62.5)$ & $18(56.3)$ & & \\
\hline \multicolumn{5}{|l|}{ Serological data received (\%) } \\
\hline No serological findings & $6(37.5)$ & $0(0)$ & \multirow[t]{4}{*}{$\chi^{2}=24.083^{*}$} & \multirow[t]{4}{*}{$<0.001^{*}$} \\
\hline Elevated ESR & $6(37.5)$ & $2(6.3)$ & & \\
\hline Elevated LDH & $0(0)$ & $2(6.3)$ & & \\
\hline Elevated ESR and elevated LDH & $4(25)$ & $28(87.5)$ & & \\
\hline \multirow[t]{2}{*}{ Clinical data } & \multicolumn{2}{|c|}{ CD274 antigen IHC in non-Hodgkin Lymphoma $\mathrm{n}=30$} & \multirow{2}{*}{ Test of Sig. } & \multirow[t]{2}{*}{$\mathrm{p}$} \\
\hline & Negative $(n=20)$ & Positive $(n=10)$ & & \\
\hline \multicolumn{5}{|l|}{ Age (years) } \\
\hline Median (Min.-Max.) & $53(48-66)$ & $63(56-64)$ & \multirow[t]{2}{*}{$\mathrm{t}=4.247^{*}$} & \multirow[t]{2}{*}{$<0.001^{*}$} \\
\hline Mean \pm SD. & $53.8 \pm 5.3$ & $61.6 \pm 3.2$ & & \\
\hline \multicolumn{5}{|l|}{ Sex $(\%)$} \\
\hline Female & $14(70)$ & $10(100)$ & $\chi^{2}=3.750$ & 0.074 \\
\hline \multicolumn{5}{|l|}{ Clinical symptoms (\%) } \\
\hline Swelling & $16(80)$ & $8(80)$ & \multirow[t]{2}{*}{$\chi^{2}=0.000$} & \multirow[t]{2}{*}{1.000} \\
\hline Fever and swelling & $4(20)$ & $2(20)$ & & \\
\hline \multicolumn{5}{|l|}{ Serological data received $(\%)$} \\
\hline No serological findings & $16(80)$ & $8(80)$ & \multirow[t]{4}{*}{$\chi^{2}=1.312$} & 0.629 \\
\hline Elevated ESR & $2(10)$ & $2(20)$ & & \\
\hline Elevated LDH & $0(0)$ & $0(0)$ & & \\
\hline Elevated ESR and elevated LDH & $2(10)$ & $0(0)$ & & \\
\hline
\end{tabular}

between the clinical presentation of $\mathrm{HL}$ and $\mathrm{NHL}$ since fever and swelling were more frequent in $\mathrm{HL}$ while swelling only was more common in NHL. Serological findings were detected more significantly in $\mathrm{HL}$ cases, with the combined elevation of both ESR and LDH being the most common finding. When comparing significant variants using univariate and multivariate logistic regression analysis affecting studied classic $\mathrm{HL}$ and DLBCL cases; age, male gender, clinical symptoms (fever and swelling), and CD274 antigen showed significant difference.

Hodgkin lymphoma is a neoplasm that is frequently seen at a young age with two peaks of incidence (third decade and older than 55) [21]. It was previously reported that there is more male incidence in $\mathrm{HL}$, especially in urban areas of Egypt [22]. Furthermore, the report of Zhou et al. showed the increased incidence of $\mathrm{HL}$ in males and the variation of $\mathrm{HL}$ incidence distribution according to age, gender, and geographical distribution [11].

Signaling of PD-1/CD274 leads to negative regulation of $\mathrm{T}$ cell-induced immune reactions to reduce the response of effector $T$ cell. It causes peripheral $T$ cell tolerance (defend tissues against immune-induced damage). Besides binding to PD-1, the interaction of CD274 with CD80, CD86 creates inhibitory signals on $\mathrm{T}$ cells and diminishes antitumor immune response [23], [24]. CD274 antigen is variably over-expressed in different types of tumors and is suggested to play a role in suppressing local responses against the tumor cells, including lymphoma [25]. The expression of CD274 on tumor cells is related to the progression of the tumor and bad prognosis [14]. Expression of CD274 is constitutively elevated in some oncogenic cells by signaling through abnormal activation of the PI3K-AKT signaling or genetic changes and amplification that is found in $\mathrm{HL}$, which is self-regulated and not related to tumor micro-environment signaling. On the contrary, CD274 expression can be induced as part of adaptive resistance of the immune system as a reaction to active signals of antitumor immune reaction. Many cytokines can produce or sustain the expression of CD274, with IFN $\gamma$ being the most effective [23].

PD-1/CD274 antigen pathway blockade by anti-PD-1/CD274 antigen antibodies has been studied for their potential antitumor immune-therapeutic role [26]. Such blockade of the PD-1/CD274 pathway using antibodies inhibitors interrupts the PD-1 axis hence converses the suppression of $T$ cells, revitalizing the drained cells of immunity in the tumor microenvironment and eradicating malignant cells. Thus, this strategy of treatment stabilizes immunity defects against the tumor, which has reached a $10-40 \%$ success in clinical response [23], [24]. For example, Atezolizumab (MPDL3280) IgG1 monoclonal antibody eradicates cellular cytotoxicity related to antibodies to avoid exhaustion of $T$ cells expressing CD274. Furthermore, it interrupts the interaction of CD274, precisely on the surface of neoplastic cells and tumor micro-environment immune cells. Hence, it improves the CD8+ T cells level by prompting cytokine increase of IFN $\gamma$, IL-18, and CXCL11 and decreasing the immune inhibition signals in the tumor's micro-environment [23].

More than half of all studied lymphoma cases (53.8\%) showed positive CD274 antigen expression. However, there was a significant difference when comparing CD274 antigen-positive, and negative cases in classic $\mathrm{HL}$ and $\mathrm{NHL}$ (DLBCL) as two-third of HL cases expressed CD274 antigen (66.7\%), while, one-third of NHL showed positivity $(33.3 \%)(p=0.004)$. 
These results were in concordance with other reports showing more frequent expression of CD274 antigen in $\mathrm{HL}$ than NHL. CD274 antigen was expressed in $31 \%$ of DLBCL compared to $70 \%$ of classic $\mathrm{HL}$ in the research done by Menter and coworkers [17]. According to another research, $82 \%$ of $\mathrm{HL}$ expressed CD274 antigen, while only $10 \%$ of DLBCL showed CD274 antigen expression [27]. The variation in DLBCL expression was mostly related to the variation in sample size, cutoff point and analyzed cells. The cutoff applied in different studies, showed a range from $5 \%$ to $30 \%$, and the cell compartment that was analyzed varied in different reports (tumor vs. nontumor cells) [28], [29], [30]. In previous studies, the use of more than $30 \%$ of tumor cells as a cutoff point resulted in $10.5-11 \%$ of DLBCL tumor cells' expression of CD274 antigen [15], [16]. While, when more than $10 \%$ of tumor cells were considered positive, $41-61 \%$ of DLBCL had CD274 antigen positivity [19], [31]. More than $5 \%$ positivity was used as a cutoff point in other studies [17], [29]. This discrepancy in detecting CD274 antigen may indicate the need for agreement and consensus on settling a definite cutoff in studying the expression of CD274 antigen in lymphoma, and we support the application of $10 \%$ as a cutoff point when considering positivity as an appropriate protocol of assessment.

In this study, there was a significant difference when comparing different intensities of CD274 antigen expression in classic $\mathrm{HL}$ and $\mathrm{NHL}$ (DLBCL) patients $(p<0.001)$. The strong intensity was common in classic $\mathrm{HL}$ cases $(50 \%)$. This result conforms to the finding of strong positivity in classic $\mathrm{HL}$ cases compared with other studied types by Vranic et al. [28].

Almost half of the peri-tumor microenvironment cells $(48.7 \%)$ showed positive CD274 antigen expression with significantly more frequent expression in classic HL cases ( $p=0.002)$. In comparison, slightly more than a quarter of peri-tumor cells showed positivity for CD274 antigen in NHL (26.7\%). The overall immunosuppressive micro-environment occurring with tumorigenesis explains the CD274 antigen detection on non-malignant infiltrating macrophages and lymphocytes besides malignant cells [19], [31]. This peri-tumoral expression finding supported other authors' reports of classic HL cells recruitment and induction of a CD274 antigen-positive myeloid environment, mainly macrophages [30]. Furthermore, other studies detected that micro-environment CD274 antigen-positive cells in DLBCL ranged from $14 \%$ to $27 \%$ [6], [15], [16], [29], [30], [31]. Moreover, high expression of CD274 antigen in NHL tumor-infiltrating lymphocytes was evident in previous studies [31]. Expression of CD274 antigen in both tumor and peri-tumor cells contributes to immune response suppression in the local environment. It is proposed that CD274 antigen-positive non-tumor cells are significant in immune therapy [32]
In this work, when comparing positive and negative CD274 antigen cases in relation to different clinical parameters, only serological findings showed significant difference $(p<0.001)$, while the same comparison in cases of classic HL showed a significant difference in male gender in addition to serological findings $(p=0.039$ and $p<0.001$ respectively). Furthermore, when comparing positive and negative CD274 antigen staining results in different parameters of the NHL (DLBCL) group, only age showed a significant difference $(p<0.001)$. These results indicate the association between CD274 antigen expression and serological data (combined elevated ESR and LDH) in lymphoma with particular significance in classic HL. The elevated ESR is one of the known bad prognostic factors in early-stage $\mathrm{HL}$, while the male gender is considered one of the established bad prognostic factors in the advanced stage of $\mathrm{HL}$ [33] that reflects a bad prognostic indication of CD274 antigen expression in classic HL cases.

There are some limitations to the current work since this was a retrospective study conducted in a single center with a sample size of 78 cases (48 cases of classic HL and 30 cases of NHL DLBCL) and limited access to clinical data. Hence, further prospective research with a larger number of cases and inclusion of other clinicopathological criteria, for example survival, size of the tumor, and EBV status, is required to confirm the prognostic value of CD274 antigen immunohistochemical expression in such cases.

\section{Conclusion}

Since CD274 antigen was expressed in 53.8\% of all studied lymphoma cases with a significantly more frequent expression of CD274 antigen in classic HL (66.7\%) compared to NHL (DLBCL) $(33.3 \%)$ and more significant strong intensity of tumor cells and more expression in peri-tumor cells of HL studied cases, this immunohistochemical marker can be applied in classic HL. CD274 reflects a bad prognostic indication in classic $\mathrm{HL}$ due to significant association with elevated ESR and $\mathrm{LDH}$ and male gender. Therefore, the high expression of CD274 antigen in classic HL proposes its potential use as a marker, especially for prognostic indication.

\section{References}

1. Ishida Y, Agata Y, Shibahara K, Honjo T. Induced expression of PD-1, a novel member of the immunoglobulin gene superfamily, upon programmed cell death. EMBO J. 1992;11(11):3887-95. PMid:1396582 
2. Mittendorf EA, Philips AV, Meric-Bernstam F, Qiao N, Wu Y, Harrington $\mathrm{S}$, et al. PD-L1 expression in triple-negative breast cancer. Cancer Immunol Res. 2014;2(4):361-70. 10.1158/23266066.CIR-13-0127

\section{PMid:24764583}

3. Faraj SF, Munari E, Guner G, Taube J, Anders R, Hicks J, et al. Assessment of tumoral PD-L1 expression and intratumoral CD8+ T cells in urothelial carcinoma. Urology. 2015;85(3):703. e1-6. 10.1016/j.urology.2014.10.020

PMid:25733301

4. Rittmeyer A, Barlesi F, Waterkamp D, Park K, Ciardiello F, von Pawel $\mathrm{J}$, et al. Atezolizumab versus docetaxel in patients with previously treated non-small-cell lung cancer (OAK): A phase 3 , open-label, multicentre randomised controlled trial. Lancet. 2017;389(10066):255-65.

5. Herbst RS, Soria J, Kowanetz M, Fine GD, Hamid O, Kohrt HE, et al. Predictive correlates of response to the anti-PD-L1 antibody MPDL3280A. Nature. 2014;515(7528):563-7. 10.1038/ nature14011

PMid:25428504

6. Patel SP, Kurzrock R. PD-L1 expression as a predictive biomarker in cancer immunotherapy. Mol Cancer Ther. 2015;14(4):847-56. 10.1158/1535-7163.MCT-14-0983 PMid:25695955

7. Miranda-Filho A, Piñeros $M$, Znaor A, Marcos-Gragera $R$, Steliarova-Foucher E, Bray F. Global patterns and trends in the incidence of non-Hodgkin lymphoma. Cancer Causes Control. 2019;30(5):489-99. 10.1007/s10552-019-01155-5 PMid:30895415

8. Li S, Young KH, Medeiros LJ. Diffuse large B-cell lymphoma. Pathology. 2018;50(1):74-87. 10.1016/j.pathol.2017.09.006 PMid:29167021

9. Hans CP, Weisenburger DD, Greiner TC, Gascoyne RD, Delabie J, Ott G, et al. Confirmation of the molecular classification of diffuse large B-cell lymphoma by immunohistochemistry using a tissue microarray. Blood. 2004;103(1):275-82. 10.1182/ blood-2003-05-1545

PMid: 14504078

10. Chan A, Dogan A. Prognostic and predictive biomarkers in diffuse large B-cell lymphoma. Surg Pathol Clin. 2019;12(3):699-707. 10.1016/j.path.2019.03.012 PMid:31352982

11. Zhou L, Deng Y, Li N, Zheng Y, Tian T, Zhai Z, et al. Global, regional, and national burden of Hodgkin lymphoma from 1990 to 2017: Estimates from the 2017 global burden of disease study. J Hematol Oncol. 2019;12(1):107. 10.1186/s13045-019-0799-1 PMid:31640759

12. World Health Organization. IARC, Egypt, Globocan 2020, (n.d.). Available from: https://gco.iarc.fr/today/data/factsheets/ populations/818-egypt-fact-sheets.pdf [Last accessed on 2021 May 22].

13. Ansell SM. Hodgkin lymphoma: 2018 update on diagnosis, risk-stratification, and management. Am J Hematol. 2018;93(5):704-15. 10.1002/ajh.25071

PMid:29634090

14. Li Y, Wang J, Li C, Ke XY. Contribution of PD-L1 to oncogenesis of lymphoma and its RNAi-based targeting therapy. Leuk Lymphoma. 2012;53(10):2015-23. 10.3109/10428194.2012.673228 PMid:22462616

15. Chen BJ, Chapuy B, Ouyang J, Sun HH, Roemer MG, Xu ML, et al. PD-L1 expression is characteristic of a subset of aggressive B cell lymphomas and virus-associated malignancies. Clin Cancer Res. 2014;19(13):3462-73. 10.1158/1078-0432. CCR-13-0855

\section{PMid:23674495}

16. Kiyasu J, Miyoshi H, Hirata A, Arakawa F, Ichikawa A Niino D, et al. Expression of programmed cell death ligand 1 is associated with poor overall survival in patients with diffuse large B-cell lymphoma. Blood. 2015;126(19):2193-201. 10.1182/ blood-2015-02-629600

PMid:26239088

17. Menter T, Bodmer-Haecki A, Dirnhofer S, Tzankov A. Evaluation of the diagnostic and prognostic value of PDL1 expression in Hodgkin and B-cell lymphomas. Hum Pathol. 2016;54:17-24. 10.1016/j.humpath.2016.03.005 PMid:27045512

18. Glinsmann-Gibson B, Wisner L, Stanton M, Larsen B, Rimsza L, Maguire A. Recommendations for tissue microarray construction and quality assurance. Appl Immunohistochem Mol Morphol. 2019;28(4):325-330. 10.1097/PAI.0000000000000739 PMid:31033496

19. Kwon D, Kim S, Kim PJ, Go H, Nam SJ, Paik JH, et al Clinicopathological analysis of programmed cell death 1 and programmed cell death ligand 1 expression in the tumour microenvironments of diffuse large $B$ cell lymphomas. Histopathology. 2016;68(7):1079-89. 10.1111/his.12882 PMid:26426431

20. Caponetti G, Bagg A. Demystifying the diagnosis and classification of lymphoma: A hematologist/oncologist's guide to the hematopathologist's galaxy. J Community Support Oncol. 2017;15(1):43-8

21. Bröckelmann PJ, Eichenauer DA, Jakob T, Follmann M, Engert $A$, Skoetz N. Hodgkin lymphoma in adults diagnosis, treatment, and follow-up. Dtsch Arztebl Int. 2018;115(31-32):535-40. 10.3238/arztebl.2018.0535

PMid:30149835

22. Herzog CM, Dey S, Hablas A, Khaled HM, Seifeldin IA, Ramadan M, et al. Geographic distribution of hematopoietic cancers in the nile delta of Egypt. Ann Oncol. 2012;23(10):2748-55. 10.1093/annonc/mds079 PMid:22553197

23. Akinleye A, Rasool Z. Immune checkpoint inhibitors of PD-L1 as cancer therapeutics. J Hematol Oncol. 2019;12(1):92. 10.1186/ s13045-019-0779-5

PMid:31488176

24. Zou W, Wolchok JD, Chen L. PD-L1 (B7-H1) and PD-1 pathway blockade for cancer therapy: Mechanisms, response biomarkers, and combinations. Sci Transl Med. 2016;8(328):328rv4. 10.1126/scitranslmed.aad7118 PMid:26936508

25. Ghosh C, Luong G, Sun Y. A snapshot of the PD-1/PD-L1 pathway. J Cancer. 2021;12(9):2735-46. 10.7150/jca.57334 PMid:33854633

26. Armand P, Nagler A, Weller EA, Devine SM, Avigan DE, Bin CY, et al. Disabling immune tolerance by programmed death-1 blockade with pidilizumab after autologous hematopoietic stem-cell transplantation for diffuse large b-cell lymphoma: Results of an international phase II trial. J Clin Oncol. 2013;31(33):4199-206. 10.1200/JCO.2012.48.3685 PMid:24127452

27. Panjwani PK, Charu $V$, DeLisser $M$, Molina-Kirsch $H$, Natkunam Y, Zhao S. Programmed death-1 ligands PD-L1 and PD-L2 show distinctive and restricted patterns of expression in lymphoma subtypes. Hum Pathol. 2018;71:91-9. 10.1016/j. humpath.2017.10.029

PMid:29122656

28. Vranic S, Ghosh N, Kimbrough J, Bilalovic N, Bender R, Arguello $D$, et al. PD-L1 status in refractory lymphomas. PLoS One. 2016;11(11):e0166266. 10.1371/journal.pone.0166266 


\section{PMid:27861596}

29. Xing W, Dresser $\mathrm{K}$, Zhang $\mathrm{R}$, Evens AM, Yu H, Woda BA et al. PD-L1 expression in EBV-negative diffuse large B-cell lymphoma: Clinicopathologic features and prognostic implications. Oncotarget. 2016;7(37):59976-86. 10.18632/ oncotarget. 11045

PMid:27527850

30. Taylor JG, Clear AJ, Truelove E, Calaminici M, Gribben JG. Beyond exhaustion: The PDL1-PD1 axis shapes the classical hodgkin lymphoma microenvironment. Blood. 2019;134(Suppl 1):658-8.

31. Gravelle P, Burroni B, Péricart S, Rossi C, Bezombes C
Tosolini $\mathrm{M}$, et al. Mechanisms of PD-1/PD-L1 expression and prognostic relevance in non-Hodgkin lymphoma: A summary of immunohistochemical studies. Oncotarget. 2017;8(27):44960-75. 10.18632/oncotarget.16680 PMid:28402953

32. Wei Y, Xiao X, Lao XM, Zheng L, Kuang DM. Immune landscape and therapeutic strategies: New insights into PD-L1 in tumors. Cell Mol Life Sci. 2021;78(3):867-87. 10.1007/s00018-020-03637-1 PMid:32940722

33. Ozuah NW, LaCasce AS. Clinical evaluation and management of hodgkin lymphoma. In: Concise Guide to Hematology. Berlin, Heidelberg: Springer International Publishing; 2019. p. 371-8. 